\title{
POLÍTICAS DE DESENVOLVIMENTO E INDÚSTRIA EM MINAS GERAIS: ANÁLISE DOS DISTRITOS INDUSTRIAIS DE UBERABA-MG
}

\author{
Marcos Kazuo Matushima \\ Professor da Universidade Federal do Triângulo Mineiro \\ Instituto de Educação, Letras, Artes, Ciências Humanas e Sociais, Uberaba - MG \\ mkmatushima@gmail.com \\ Thiago de Jesus Sousa \\ Graduado em Geografia pela Universidade Federal do Triângulo Mineiro \\ Instituto de Educação, Letras, Artes, Ciências Humanas e Sociais, Uberaba - MG \\ tjs tst2008@hotmail.com
}

\begin{abstract}
RESUMO
O município de Uberaba tem se destacado como polo industrial do interior do estado de Minas Gerais, apresentando um crescimento industrial importante a partir da década de 1970, com a expansão da fronteira agrícola e do processo de desconcentração industrial que ocorreu no Brasil. Neste artigo, será analisado esse modelo de industrialização, que através de incentivos fiscais e da oferta de infraestrutura e terrenos atraíram diversas empresas e indústrias para o município, o que gerou diversos impactos econômicos, ambientais e sociais. O município de Uberaba conta hoje com três distritos industriais em atividade e um quarto distrito em implantação. Cada um dos distritos conta com empresas de vários segmentos de atividades industriais, como químico, alimentício, metalúrgico, moveleiro, etc., destacando-se as indústrias ligadas a produção de fertilizantes e insumos agrícolas, que se começaram a se instalar no final da década de 1970, tornando atualmente o município um dos principais polos de produção de fertilizantes químicos do país.
\end{abstract}

Palavras-chave: Industrialização. Distrito Industrial. Desenvolvimento econômico.

\section{DEVELOPMENT AND INDUSTRIALIZATION POLICIES IN MINAS GERAIS: ANALYSIS OF THE INDUSTRIAL DISTRICTS OF UBERABA-MG}

\begin{abstract}
The city of Uberaba has stood out as an industrial pole in the interior of the state of Minas Gerais, presenting an important industrial growth since the 1970s, with the expansion of the agricultural frontier and the industrial deconcentration process that occurred in Brazil. In this article, this model of industrialization will be analyzed, which through tax incentives and the offering of infrastructure and land attracted several companies and industries to the municipality, which generated several economic, environmental and social impacts. The municipality of Uberaba today has three industrial districts in operation and a fourth district being implemented. Each of the districts has companies from various segments of industrial activities, such as chemical, alimentary, metallurgical, furniture, etc., with emphasis on the industries related to the production of fertilizers and agricultural inputs, which began to be installed at the end of the decade 1970, making currently the city one of the country's main chemical fertilizer production hubs.
\end{abstract}

Keywords: Industrialization. Industrial District. Economic development.

\section{INTRODUÇÃO}

Nos últimos anos, observamos um grande crescimento do setor industrial no interior brasileiro, principalmente nas cidades de porte médio ${ }^{1}$. Esse processo de industrialização veio a se destacar a

1 O IBGE usa como critério o Censo Demográfico para classificar o porte das cidades, e considera como cidades médias aquelas que possuem entre 100 e 500 mil habitantes.

$\begin{array}{lllll}\text { Caminhos de Geografia } \quad \text { Uberlândia-MG } & \text { v. 22, n. } 80 & \text { abr./2021 } & \text { p. 309-323 Página } 309\end{array}$


partir da década de 1970, com a implantação de políticas de desconcentração industrial, promovidas pelo Estado. O Brasil teve um desenvolvimento industrial tardio em comparação com outros países capitalistas, tendo o crescimento da atividade industrial ocorrido após a Segunda Guerra Mundial.

O município de Uberaba teve um grande crescimento no setor industrial a partir da década de 1970, quando foram criados três distritos industriais; anteriormete, como em grande parte do interior brasileiro, o município não apresentava destaque no setor industrial. Após a década de 1970 com o processo de desconcentração industrial e a expansão da fronteira agrícola, o município passa a ter um grande destaque no cenário econômico nacional a partir de investimentos realizados pelo Estado, através de políticas públicas.

Com a expansão da fronteira agrícola, a região do Triângulo Mineiro e Alto Paranaíba passou por um grande desenvolvimento econômico e industrial, com a instalação de várias indústrias, ligadas principalmente ao setor agropecuário, como a antiga Fosfértil (hoje Mösaic Fertilizantes), Heringer entre outras, Uberaba passa a ter grande destaque por sua logística diferenciada, estando em um raio de $500 \mathrm{~km}$ de distância de importantes capitais brasileiras como Belo Horizonte, São Paulo, Goiânia e Brasília.

A pesquisa foi baseada em pesquisa bibliográfica do tema (livros e artigos científicos), consultas em sites oficiais na internet para coleta de dados, além de dados coletados junto a secretaria de desenvolvimento econômico e turismo do município de Uberaba.

O presente artigo busca analisar a origem do processo de industrialização de Uberaba, através do papel dos distritos industriais. O texto aborda primeiramente a industrialização no Brasil e em Minas Gerais e posteriormente apresenta uma análise dos Distritos Industriais localizados no município de Uberaba.

\title{
ALGUNS APONTAMENTOS SOBRE O PROCESSO DE INDUSTRIALIZAÇÃO NO BRASIL
}

A economia brasileira, passou por diversas transformações ao longo da história, tendo como destaque a agricultura, que antes do processo de industrialização era a responsável por movimentar a economia do país. Além do café, produtos como cacau, açúcar e algodão foram responsáveis por grande parcela da riqueza produzida no país,.

\begin{abstract}
Um dos mais importantes fatos da moderna fase da economia agrária brasileira é o processo de retalhamento da propriedade fundiária rural e o aparecimento, em escala crescente, da pequena propriedade, quase ausente no passado. Nos primeiros séculos da colonização, não havia lugar senão excepcionalmente para esse tipo de propriedade numa economia como a nossa, voltada exclusivamente para a exploração em larga escala de produtos de alto valor comercial como o açúcar, o algodão, o café, a borracha, o cacau; e assente no trabalho de escravos ou semi-escravos que formavam a massa camponesa do país. (PRADO JUNIOR, 2006, p 188)
\end{abstract}

No início do século $X X$ no Brasil, as primeiras atividades industriais no foram as baseadas na manufatura de bens de consumo não duráveis, sendo que havia grande predominância de indústrias do setor têxtil, representadas por pequenas oficinas onde não havia um grau avançado de mecanização. Mesmo assim, o setor têxtil empregava uma grande quantidade de trabalhadores nesse período, o que mostrava que o Brasil era um país relativamente atrasado em relação ao setor industrial, pois somente a indústria têxtil tinha uma certa importância. (VERSIANI e SUZIGAN, 1990).

Além da indústria têxtil, onde predominava a produção de tecido de algodão, o ramo alimentar teve grande significação no início do século XX. Apresentava-se também bastante disperso geograficamente e muito diversificado quanto aos sub-ramos. Certos segmentos ainda mantinham características fortemente manufatureiras, como os estabelecimentos produtores de banha de porco e sobretudo as charqueadas, muito numerosas no Rio Grande do Sul, onde as maiores unidades empregavam centenas de trabalhadores. (MAMIGONIAM 2000, p.8). 
O início da década de 1920 ainda sentiu os reflexos econômicos deixados pela Primeira Guerra Mundial, onde o país buscou, através de novas tecnologias, outros meios para o seu desenvolvimento industrial.

O debate sobre a década de 1920 segue, até certo ponto, linhas simétricas ao da Primeira Guerra. Essa década presenciou uma tendência á estagnação no principal setor industrial, o de produção têxtil o que levou vários autores a rotulá-la como uma fase negativa para o processo de industrialização. (VERSIANI e SUZIGAN, 1990, p. 9).

No período entre o final da Primeira Guerra até o início da década de 1930, houve intenso processo de diversificação industrial, o que foi benéfico para a economia do país. Iniciou-se a fabricação de máquinas têxteis, motores elétricos, cimento, implementos agrícolas entre outros produtos. As classes de industriais desse período eram formados principalmente por imigrantes europeus que haviam trazido certas experiências da indústria europeia, o que trouxe um avanço para a industrialização brasileira, sendo que esse avanço veio principalmente através das dificuldades de importação no período da Primeira Guerra Mundial, o que obrigou a indústria brasileira se reinventar (VERSIANI; SUZIGAN, 1990).

No Brasil, R. Simonsen destacou a conjuntura da Primeira Guerra Mundial e da crise de 1929 como favorável à industrialização, em vista da incapacidade de importação do Brasil, inaugurando entre nós a visão de uma industrialização que se impulsionava nos momentos de crise das relações centro/periferia, substituindo importações tornadas problemáticas pela queda das nossas exportações. (MAMIGONIAM, 2000, p.8).

Após esse período de crise, o, houve uma fase de transição entre o período da Primeira Guerra e a Grande Depressão, em que o Estado tomou medidas para implantar incentivos para a indústria, fato que através da implantação de políticas de desenvolvimento, proporcionaria o crescimento econômico do país.

A essa nova postura correspondeu a adoção de várias medidas concretas de incentivo a determinados setores de atividade industrial, como a produção de ferro e aço, soda cáustica, borracha, adubos, cimento, seda e subprodutos do algodão e ainda a extração de carvão mineral. (VERSIANI; SUZIGAN 1990, p. 11).

Os estímulos para indústria passaram a ser uma das principais medidas políticas adotadas pelo Estado para o desenvolvimento econômico do país. Após passar por um longo período de recessão na década de 1930, o Estado brasileiro passa a aplicar medidas para um novo modelo de desenvolvimento industrial. A grande crise de 1929 afetou de forma expressiva a maior fonte de exportação brasileira, o café, arruinando a oligarquia cafeeira paulista, que vinha sofrendo grandes pressões de grupos urbanos e outras oligarquias regionais por mudanças. A Revolução de 1930 e a presidência de Getúlio Vargas, trouxe uma nova visão econômica para o país, focando os esforços no processo de industrialização e deixando de lado a grande dependência do café.(VERSIANI; SUZIGAN, 1990).

No período entre a década de 1930 até meados a década de 1950, o Estado brasileiro passou a adotar políticas públicas para impulsionar o crescimento econômico do país, como políticas comerciais de proteção da produção industrial interna, além de ensaios para o planejamento industrial, com o Estado como produtor direto de alguns setores industriais onde não havia capital privado suficiente. Esse novo modelo baseado na substituição de importações, imposto pela crise de 1929, trouxe diversas mudanças, sendo a principal a restrição na importação de bens industrializados em virtude da falta de recursos, gerando uma mudança no cenário da indústria brasileira (MAMIGONIAN, 2000).

Segundo Versiani e Suzigan (1990), através dessas políticas, o Brasil passou a ter um grande crescimento industrial nas seguintes áreas: indústrias químicas, siderúrgicas, energia elétrica, fabricação de motores pesados. 
Somente a partir da década de 1950 o Brasil passa a ter políticas de desenvolvimento econômico integradas ao desenvolvimento industrial. O país passou a investir nos setores de transporte, indústria, agricultura e energia, o que levou a criação do BNDE (Banco Nacional do Desenvolvimento Econômico), que veio a desempenhar um grande papel no desenvolvimento dos setores de transportes, indústrias, infraestrutura entre outros, (VERSIANI e SUZIGAN, 1990).

Houve nesse período a implantação de algumas medidas que impulsionaram o desenvolvimento industrial no país, destacar destacando-se a criação da PETROBRAS em 1953, que permitiu o desenvolvimento das atividades de refino de petróleo no país. O Estado estava disposto a desenvolver o setor industrial brasileiro, além da criação da PETROBRAS, houve também em 1953 a implementação da instrução 70 da SUMOC (Superintendência da Moeda e do Crédito), que promoveu transformações no regime de importações e da política cambial.

Através do estabelecimento de um sistema de taxas múltiplas de câmbio, as importações passaram a ser classificadas em cinco categorias distintas, cada uma correspondente a uma taxa de câmbio específica que se distinguia das demais de acordo com o grau de essencialidade atribuído à mercadoria importada, (MARKOSKI, 2009, p. 36).

Porém somente após a criação e implantação do Plano de Metas em 1956, houve coordenação e organização do desenvolvimento industrial do país, destaca-se nesse período a instalação de indústrias automobilísticas, além dos investimentos em infraestrutura, o que consequentemente impulsionou outros setores em uma reação em cadeia (VERSIANI; SUZIGAN, 1990). A vinda da empresa alemã Volkswagen em São Bernardo do Campo foi um grande marco para o desenvolvimento Industrial brasileiro.

Nesse período entre o início do século XX e até meados da década de 1950, o Brasil conseguiu criar uma identidade industrial, mesmo tendo que passar por algumas crises.

No período entre 1963 até 1967 o país entrou em um período de recessão, sendo que após esse período foi feita uma reorganização da política industrial, que demostrou sinais de um novo crescimento a partir de 1968. (VERSIANI e SUZIGAN, 1990, p. 18)

Com a política de expansão industrial e com investimentos públicos em vários setores (comunicação, transporte, energia, além de investimentos em siderúrgicas, petroquímicas entre outras), esse período da década de 1950 a década de 1970 foi marcado por uma reforma econômica realizada para a atração de investimentos internacionais. A indústria brasileira recebeu grandes investimentos do setor privado, sendo que na segunda metade da década de 1970 a produção industrial teve uma queda, sendo que entre 1975/1979, com o II Plano nacional de Desenvolvimento, foram retomados os investimentos em vários setores, tendo como objetivo a exportação de alguns insumos, além de agregar valor a produtos da indústria brasileira.

Na década de 1980 houve a pior recessão da história brasileira, com grande redução da produção industrial, além de um aumento da taxa de desemprego, o país procurou se reinventar com novas tecnologias, visando manter participação no mercado interno. Na segunda metade da década de 1980 o Estado procurou investir novamente na indústria, através de novas estratégias, mas como o país não havia desenvolvido o setor de tecnologia se comparado ao mercado internacional, o setor industrial começou a perder participação no PIB. Segundo Versiani e Suzigan, (1990), o Brasil não havia promovido políticas de desenvolvimento científico, tecnológico e formação de recursos humanos, o que consequentemente, deu origem a uma indústria pouco competitiva nos mercados internacionais.

A industrialização perde a sua força nesse período, o que desencadeou uma grande recessão no final da década de 1980, houve estagnação da indústria, que não conseguiu se reestruturar para e acompanhar a indústria internacional, fazendo o país sofrer uma grande recessão no setor industrial, pois o Brasil passava por grandes dificuldades econômicas durante esse período. 


\title{
O DESENVOLVIMENTO DA INDÚSTRIA EM MINAS GERAIS E NO TRIÂNGULO MINEIRO
}

A economia do estado de Minas Gerais durante o período colonial era baseado na mineração aurífera, que foi uma das principais fontes de economia do Brasil Colonial. Com a decadência da exploração mineral entre o final do século XVIII e o início do século XIX, houve uma mudança econômica, desenvolvendo a participação da produção de gêneros alimentícios, que durante o século XIX foi a principal fonte econômica no estado.

\begin{abstract}
A Chegada e a fixação da corte português na colônia, a partir de 1808 impulsionará a produção e o comercio de gêneros alimentícios, transformando o Rio de Janeiro no principal polo receptor desta produção, e responsável pela formação de um incipiente mercado interno. Isto pois, a região sul de Minas Gerais se transformará, durante toda a primeira metade do século XIX, no centro dinâmico da economia mineira, com a produção mercantil de gêneros alimentícios, tendo na grande propriedade e no trabalho compulsório, sua base produtiva. (PAULA, 2002, p.3).
\end{abstract}

Com o crescimento da agricultura, principalmente da região do vale do Paraíba Fluminense, a região da Zona da Mata Mineira veio a se destacar no setor de cafeicultura, sendo o centro dinâmico para essa nova atividade econômica da província de Minas gerais, sendo que podemos destacar o desenvolvimento do sistema viário, fator que melhorou de forma significante o transporte da região da Zona da Mata com o porto do Rio de Janeiro por volta de 1870. A expansão da malha ferroviária foi um importante modal que influenciou o crescimento econômico não só de Minas mais de todo o Brasil, (PAULA, 2002).

Esses fatores impulsionaram o crescimento industrial de Juiz de Fora, principalmente pelo capital acumulado, que teve entre o final do século XIX até meados 1930 um surto industrial com o desenvolvimento logístico através da expansão do modal ferroviário, que foi um dos fatores predominantes para expansão industrial da cidade. A expansão do ramal ferroviário dinamizou de forma crescente a economia de Juiz de Fora, o que acabou beneficiando várias cidades da região, (PAULA, 2002).

A partir da década de 1930 vemos um deslocamento da dinâmica industrial para a zona metalúrgica, que após a crise do setor agroexportador, levou a estagnação da região da Zona da Mata Mineira, a indústria regional centralizada na cidade de Juiz de Fora não conseguiu uma nova expansão, assim perdendo espaço para as indústrias de grandes centros urbanos, principalmente pelo desenvolvimento da dinâmica industrial do estado de São Paulo.

No período entre as décadas de 1930 até meados finais da década 1940, houve uma grande expansão dos complexos industriais da zona metalúrgica mineira.

\begin{abstract}
A expansão do setor minero-metalúrgico de Minas Gerais, também recebeu como efeitos de estímulo, os acontecimentos da Segunda Guerra Mundial. É em função da Guerra que alguns importantes projetos na área de mineração e metalurgia foram definidos para Minas no Início da década de 1940. O problema da exportação de Minério de Ferro passou a ser prioritário para as potencias bélicas aliadas, isto é para os Estados Unidos e a Inglaterra, daí decorrendo os chamados Acordos de Washigton e a consequente criação da Cia. Vale do Rio Doce, em 1942 (DINIZ, 1981 p. 55 apud PAULA, 2002, p. 15).
\end{abstract}

Essa expansão do setor metalúrgico trouxe um novo período de desenvolvimento para a economia mineira, que havia sofrido ciclos de depressão econômica após o fim do ciclo do ouro no século XIX e com aqueda nas exportações de café no início do século XX. sendo que esse recente modelo de industrialização trouxera uma nova dinâmica econômica para a região central do estado de Minas Gerais.

Dessa forma, a partir da década de 1950, Minas Gerais passou a se especializar no setor siderúrgico, aumentando consideravelmente a participação do capital estatal e estrangeiro no setor. A Região Central de Minas se tornou um grande centro industrial e econômico, pois as grandes indústrias do eixo Rio-São Paulo necessitavam de matérias primas exploradas em Minas Gerais, esse fator permitiu o crescimento de vários outros setores na Região Central de Minas Gerais, que se tornou o polo econômico do estado, vindo a a receber grandes investimentos estatais e privados, (PAULA, 2002). Pode-se citar como exemplo a criação da Companhia Energética de Minas Gerais (CEMIG) em 1955, e investimentos do capital internacional como da Fabbrica Italiana Automobili Torino (FIAT), que instalou uma fábrica em Betim, na região metropolitana de Belo Horizonte, durante a década de 1970. A partir da década de 1970 Minas Gerias passou a ter grande destaque econômico no Brasil.

Na região do Triângulo Mineiro, partir da segunda metade do século XIX, o município de Uberaba passa a ter um grande destaque econômico, principalmente a partir da implantação em 1888 dos

$\begin{array}{lllll}\text { Caminhos de Geografia } \quad \text { Uberlândia-MG } & \text { v. 22, n. } 80 & \text { abr./2021 } & \text { p. 309-323 Página } 313\end{array}$


trilhos da Companhia Mogiana, que expandiu sua malha ferroviária a partir do estado de São Paulo, fato que teve papel preponderante para o desenvolvimento econômico do Triângulo Mineiro, permitindo uma integração econômica com o exterior através do escoamento de produtos da região com os portos.

\begin{abstract}
A ferrovia veio reformular a organização sócio-econômica do Triângulo e, ao mesmo tempo, redefinir o papel de suas cidades na divisão regional do trabalho. A chegada desta até Uberaba significava o estabelecimento dos caminhos econômicos modernos. Estava superada a rota fluvial, que fez também de Frutal uma cidade (1885), e estabelecido o domínio de Uberaba sobre todo o território triangulino, mato-grossense e goiano. (GUIMARÃES, 2004, p. 10).
\end{abstract}

Após a inauguração dos trilhos da Companhia Mogiana em Uberaba e a expansão da ferrovia até o estado de Goiás, o Triângulo Mineiro passou a ser um nó na comercialização e distribuição de mercadorias, a grande demanda na exportação de alimentos e as relações comerciais entre São Paulo, Centro Oeste e Minas Gerais, foi primordial para o desenvolvimento regional.

A expansão ferroviária pelo Triângulo Mineiro, não resultou de determinações internas, mas de transformações econômicas e sociais que ocorrias em São Paulo. Naquela província, o advento da cafeicultura, a partir da década de 1860, trouxe, sem dúvida, a modernidade. Assim que a velha capital foi alcançada pelos trilhos da São Paulo Railway, em 1986, uma nova economia começou a se instalar no seu território. (LOURENÇO. 2010, p. 98).

A região do Triângulo Mineiro passou por diversas transformações antes da década de 1950, após a expansão das ferrovias, houve o desenvolvimento do modal rodoviário com a Companhia Mineira de Autoviação Intermunicipal - CMAVI, instalada em Uberlândia em 1912, além de um progresso significativo através da ampliação do sistema telégrafo. Diferentemente da região Central de Minas e a da Zona da Mata, o Triângulo Mineiro obteve um crescimento econômico consistente após a expansão da fronteira agrícola, que proporcionou a região um novo modelo econômico e industrial.

Ao longo dos anos, o estado de Minas Gerais passou a ter uma economia diversificada, sendo que a Zona da Mata, Triângulo Mineiro e a Região central de Minas têm peso expressivo na economia do Estado.

\title{
PROCESSO DE CONCENTRAÇÃO E DESCONCENTRAÇÃO INDUSTRIAL.
}

A partir da década de 1970 ocorre um grande processo de desconcentração industrial no estado de São Paulo, sendo que alguns fatores contribuíram para essa diminuição do ramo industrial no estado, como o aumento da produção industrial e instalação de grandes empresas em outros estados, como por exemplo a Zona Franca de Manaus, e a queda na produção de bens de consumos duráveis e não duráveis e vários outros setores.

A Região Metropolitana de São Paulo (RMSP), é considerada uma das maiores e mais importantes regiões metropolitanas do mundo, e se destaca por ser o maior e mais importante polo econômico e industrial da América Latina. Até meados de 1970 a Região Metropolitana de São Paulo concentrava quase toda a produção industrial do estado de São Paulo.

\begin{abstract}
No que se refere a produção da indústria de transformação, desde 1919 Sã Paulo ocupava o primeiro lugar, com $31,5 \%$ do total nacional, cifra que passaria a $58 \% \mathrm{em}$ 1970, quando atinge o auge da concentração industrial do país. Nesse ano, concentrava $53 \%$ da produção nacional da indústria de não duráveis e da de bens intermediários e $75 \%$ da de bens de capital e de consuma durável. Dos 22 ramos industriais, em 16 deles São Paulo Concentrava mais de 50\% da produção nacional. (CANO. 1997, p.113,114).
\end{abstract}

Segundo Negri (1996), internamente, o estado de São Paulo veio a ter a sua própria dinâmica de desconcentração sendo que a grande São Paulo concentrava $43,4 \%$ da produção industrial do estado 1970 , enquanto o interior era responsável por $14,7 \%$, quinze anos depois o interior já representava $22,5 \%$ enquanto a Grande São Paulo teve uma considerável queda para $29,4 \%$. A grande São Paulo que concentrava de forma hegemônica a produção industrial foi perdendo pós 1970 , grande parte de suas indústrias, que migravam cada vez mais para o interior de São Paulo, e para outros estados no Brasil. Na tabela 2 observamos que houve uma forte queda da produção industrial da região metropolitana de São Paulo e um crescimento industrial considerável no interior paulista, além do crescimento em todos os estados brasileiros. 
Esse fator foi muito importante para o interior do estado, principalmente para as cidades de porte médio, que se mostravam condições de produção mais vantajosas do que a grande São Paulo, com o custo de força de trabalho mais atrativas, preços dos terrenos mais baixos, além de incentivos fiscais entre outros fatores, formando assim novos espaços produtivos e trazendo uma nova dinâmica econômica para outras regiões do interior, podemos destacar as políticas de descentralização criadas pelo governo paulista para propiciar o desenvolvimento regional deram resultados.

\begin{abstract}
Nos últimos anos o processo de desconcentração industrial, algumas empresas industriais antes localizadas na cidade ou região metropolitana de São Paulo, por meio de incentivos fiscais de governo municipal instalaram-se em cidades médias, mas a parte de gestão continua na metrópole, como tem ocorrido com o deslocamento do "chão de fábrica" para as regiões do Triângulo Mineiro, do Norte do Paraná, nas proximidades com o estado de São Paulo e outras regiões do país ( GOMES. 2011, p.6).
\end{abstract}

Essa expansão industrial, ocorrida após a desconcentração industrial paulista, beneficiou cidades médias não só do interior paulista, mais também cidades próximas a divisa com o estado de São Paulo, por exemplo, municípios como Uberaba, Uberlândia em Minas Gerais, Três Lagoas em Mato Grosso do Sul, e cidades do norte do Paraná, como Londrina e Maringá, que obtiveram grande desenvolvimento com esse processo de desconcentração.

Esse processo trouxe uma nova estrutura econômica industrial para o interior do Brasil, levando não só indústrias para as cidades médias, e promovendo um desenvolvimento econômico em outros setores, como comércio e serviços. Essas cidades passaram a ter um destaque econômico considerável, tendo uma economia diversificada, fazendo o papel de cidades polos no interior do Brasil.

\title{
A EXPANSÃO DA FRONTEIRA AGRÍCOLA E O DESENVOLVIMENTO INDUSTRIAL DE UBERABA
}

No período entre a década de 1960 e 1970 houve o processo de modernização do setor agropecuário, que incorporou o cerrado no processo de produção agrícola, através da implantação de algumas políticas públicas, que vieram a influenciar o sistema de produção nas regiões do Triangulo Mineiro e Alto Paranaíba, podemos destacar alguns programas como: POLOCENTRO - Programa de Desenvolvimento dos Cerrados, $\mathrm{PCl}$ - Programa de Crédito Integrado e Incorporação dos Cerrados, PADAP - Programa de assentamento dirigido do Alto Paranaíba.

Esses programas, além de explorar as novas tecnologias disponíveis na época, mudaram totalmente o cenário produtivo da região, aumentando de forma considerável o uso da terra, que antes desse período de modernização e das novas tecnologias, eram pouco aproveitadas para agricultura, assim a região do Triangulo Mineiro e Alto Paranaíba passou a produzir em uma maior escala, cana de açúcar, milho e soja, a região passa então a ter um grande destaque no cenário nacional, com o uso das terras que antes eram utilizadas para pecuária de corte.

A região do Triângulo Mineiro foi marcada, ao longo do século $X X$, por um processo de diversificação produtiva, com desenvolvimento de atividades agropecuárias e da agroindústria moderna, bem como de atividades comerciais, indústrias e de serviços alterando a dinâmica das cidades médias da região, como Uberlândia e Uberaba. (GOMES. 2016, p.7).

O desenvolvimento do município de Uberaba também se deu muito pela sua localização, em um raio de $500 \mathrm{~km}$ de importantes capitais do sudeste e centro-oeste. A região do Triângulo Mineiro foi uma das regiões mais beneficiadas pela expansão da fronteira agrícola e a modernização da agricultura, além do desenvolvimento genético do gado zebu que promoveu um avanço considerável da pecuária após a década de 1970.

[...] as linhas de crédito implantadas pelo governo estavam atreladas à compra de insumos modernos, ampliando a dependência do setor produtivo agrícola ao setor produtor de insumos. O Estado fornecia incentivos e subsídios e, assim, criava demanda aos produtos do complexo agroindustrial, impulsionando os setores dinâmicos da economia, notadamente o da indústria. (PIRES, 2000, p. 116).

O setor agropecuário passa a ter uma grande demanda do consumo de Fertilizantes com a expansão da fronteira agrícola na região do cerrado brasileiro, o Estado através de políticas públicas, passou a investir na produção nacional desses insumos, na década de 1970 foi criado o Plano Nacional de

$\begin{array}{lllll}\text { Caminhos de Geografia } \quad \text { Uberlândia-MG } & \text { v. 22, n. } 80 & \text { abr./2021 } & \text { p. 309-323 Página } 315\end{array}$


Fertilizantes e Calcário Agrícola, ampliando e modernizando a indústria de fertilizantes no país. O município de Uberaba foi um dos grandes beneficiados no âmbito econômico com esse plano, com a criação do seu maior distrito industrial, o distrito industrial III, sendo um dos fatores para a instalação desse distrito foi a fabricação de fertilizantes (Tabela 1). A proximidade com a matéria prima, a rocha fosfática extraída na região da Serra da Canastra, além da logística diferenciada (ferrovias e rodovias), foram os principais fatores para a instalação dessas indústrias no município de Uberaba, que se tornou um dos principais polos de produção de fertilizantes do país (GOMES; MATUSHIMA; CHAGAS, 2017).

Tabela 1 - Uberaba: Valor adicionado bruto por setor de atividades econômica - 1999 - 2012 ( a preços concorrentes - $\mathrm{R} \$ 1.000,00$ ).

\begin{tabular}{lllll}
\hline Setor de atividade econômica & $\mathbf{1 9 9 9}$ & $\mathbf{2 0 0 5}$ & $\mathbf{2 0 1 0}$ & $\mathbf{2 0 1 2}$ \\
\hline Agropecuária & 132.740 & 371.795 & 551.237 & 685.221 \\
Indústria & 639.394 & 1.218 .820 & 2.138 .619 & 2.461 .437 \\
Serviços & 973.227 & 2.006 .740 & 3.502 .270 & 4.563 .714 \\
$\begin{array}{l}\text { administração, saúde e educação públicas } \\
\text { e seguridade social }\end{array}$ & 163.840 & 315.873 & 581.826 & 707.314 \\
\hline
\end{tabular}

Fonte - IBGE (2012)

Na tabela 1, constata-se o grande aumento no PIB de Uberaba entre 1999 a 2012, mostrando o grande crescimento em todos os setores econômicos, sobretudo do PIB industrial, que teve um crescimento inferior somente em relação ao setor de serviços. Esses dados demostram a grande importância do setor industrial no município de Uberaba, atividade mais importante que o setor agropecuário.

Em relação as atividades industriais em Uberaba, a maior parte das indústrias estão localizadas nos três distritos industriais do município, sendo o maior deles o Distrito Industrial III, que concentra as indústrias ligadas a produção de fertilizantes e produtos químicos.

\section{TIPOLOGIA DOS DISTRITOS INDUSTRIAIS}

Quando tratamos do tema referente ao processo de industrialização, observamos que há vários modelos para o estudo dos aglomerados industriais, um modelo que podemos destacar são os distritos industriais, um espaço destinado a instalações de empresas de diversos setores, sendo um modelo utilizado em diversos países.

Um dos primeiros teóricos a discutir sobre as aglomerações industriais foi o economista Alfred Marshall, que no final do século XIX elaborou um conceito de distrito industrial que podemos chamar de distritos Marshallianos.E

Marshall (1996) tinha a concepção de que a concentração de indústrias dos mesmos setores, fabricando um mesmo tipo de produto, traria uma certa facilidade em relação a mão de obra especializada, que posteriormente atrairia uma grande quantidade de empresas para aquele distrito, formando um processo de integração com as empresas ali localizadas, levando em questão de logística uma facilidade para as empresas instaladas naquele distrito, um modelo de integração que seria beneficiado por uma mão de obra qualificada, que adotaria um modelo cooperação entre as empresas do mesmo ramo localizadas nesses distritos.

Essa teorização sobre o distrito industrial marshalliano não corresponde completamente à realidade brasileira, onde o termo "distrito industrial" está mais ligado à intervenção do Estado na produção dos espaços destinados às atividades industriais. (MATUSHIMA, 2005, p.142).

Para Marshall (1996), a concentração industrial em locais específicos se deve a vários fatores entre eles: proximidades a fontes de matéria-prima, mão de obra qualificada, ambiente político e econômico 
favorável para o desenvolvimento da industria. O autor não teoriza de forma clara sobre o papel do Estado na questão da produção do espaço industrial.

Markusen (1995) teoriza sobre a questão dos distritos industriais, que para a autora, o distrito industrial é uma área espacialmente delimitada, com uma nova orientação de atividade econômica de exportação e especialização definida, seja ela relacionada a base de recursos naturais, ou acertos tipos de indústria ou serviços.

Segundo Markusen (1995), podemos destacar 4 tipos de distritos, cada um com a sua particularidade e características:

1 - Distritos Marshallianos: Baseado nos modelos de distritos do economista Alfred Marshall, os distritos Marshallianos são formados por uma determinada concentração de pequenas empresas, em que há relações entre essas empresas com uma determinada área ou localidade, empresas de pequeno porte de pequenas produções com uma economia local e flexível, com mínimas relações com indústrias fora dos distritos.

2 - Distritos Centro Raio: Nos seguintes distritos as empresas de grande porte têm amplo domínio, contendo uma forte integração entre si, são basicamente abastecidas por pequenos fornecedores e as empresas principais se localizam fora dos distritos, e possuem uma pequena relação com empresas competidoras.

3 - Plataforma Satélite: Esse modelo de distrito tem uma grande participação do Estado através de incentivos fiscais, fornecimento de total infraestrutura entre outros benefícios, muitas das vezes é instalado fora de grandes centros urbanos, esses benefícios gerados pelo governo na maioria das vezes visa o desenvolvimento de uma determinada região, podemos colocar como exemplo a zona franca de Manaus, antes da instalação da mesma a região carecia de industrialização forte como a de grandes centros e de outras regiões do Brasil, podemos levar em conta as questões de impostos e remuneração que são bem mais atrativos se comparados aos grandes centros, as empresas localizadas nesses distritos são dirigidas por grandes corporações multinacionais localizadas principalmente em países como Japão e Estados Unidos.

4 - Distritos ancorados pelo Estado: É baseado através de instituições de base governamental, como centros de pesquisas de bases militares e universidades, os mesmos basicamente são voltados a área de pesquisas, industrias militares entre outros, que posteriormente atrairá empresas que complementará os trabalhos ali existentes, nos EUA podemos apontar algumas cidades que adotam esse modelo de distrito, Santa fé, Albuquerque e San Diego, esse modelo contribuiu consideravelmente para o desenvolvimento da cidade de Los Angeles, através de pesquisas militares, esse modelo é adotado na cidade de São José dos Campos através do complexo aero espacial.

No Brasil houve a criação de políticas públicas pelo Estado brasileiro para atração de indústrias nacionais e multinacionais em várias regiões do país. O município de Uberaba adotou esse modelo de políticas públicas visando a atração indústrias para o município, o modelo que mais se adequa aos distritos da cidade de Uberaba são os de Plataforma satélite, já que os distritos foram implantados a partir da década de 1970, através do II PND (Plano Nacional de Desenvolvimento). Essa política de atração continuou nas próximas décadas, com a aprovação de legislação municipal para atração de empresas, como por exemplo a Lei Municipal 6.889, de 17/12/1998 que após a nova redação alterou para a Lei 9.110 de 24 de Dezembro de 2003, fornece as empresas que queiram se instalar no município incentivos fiscais, visando o desenvolvimento econômico de Uberaba, as empresas instaladas nos Distritos, além de incentivos recebe toda a infraestrutura necessária para sua instalação.

Como abordado, os distritos do município de Uberaba foram criados no final da década de 1970 , justamente no período de expansão da fronteira agrícola e o processo de desconcentração industrial no Brasil que ocorreu na década de 1970 que se expandiu de São Paulo para o interior do Brasil. As questões relacionadas com a infraestrutura foram predominantes para essa expansão, além do desenvolvimento econômico de Uberaba, as políticas governamentais trouxeram uma nova realidade para região.

Atualmente Uberaba conta com três distritos industriais em funcionamento (Figura 1) e um distrito em implantação, criados e planejados com uma ampla infraestrutura, os mesmos apresentam um modal rodoviário privilegiado, além de contar com ferrovias com ligação em diversas regiões do Brasil. 
Figura Erro! Nenhuma sequência foi especificada. - Localização dos Distritos Industriais.

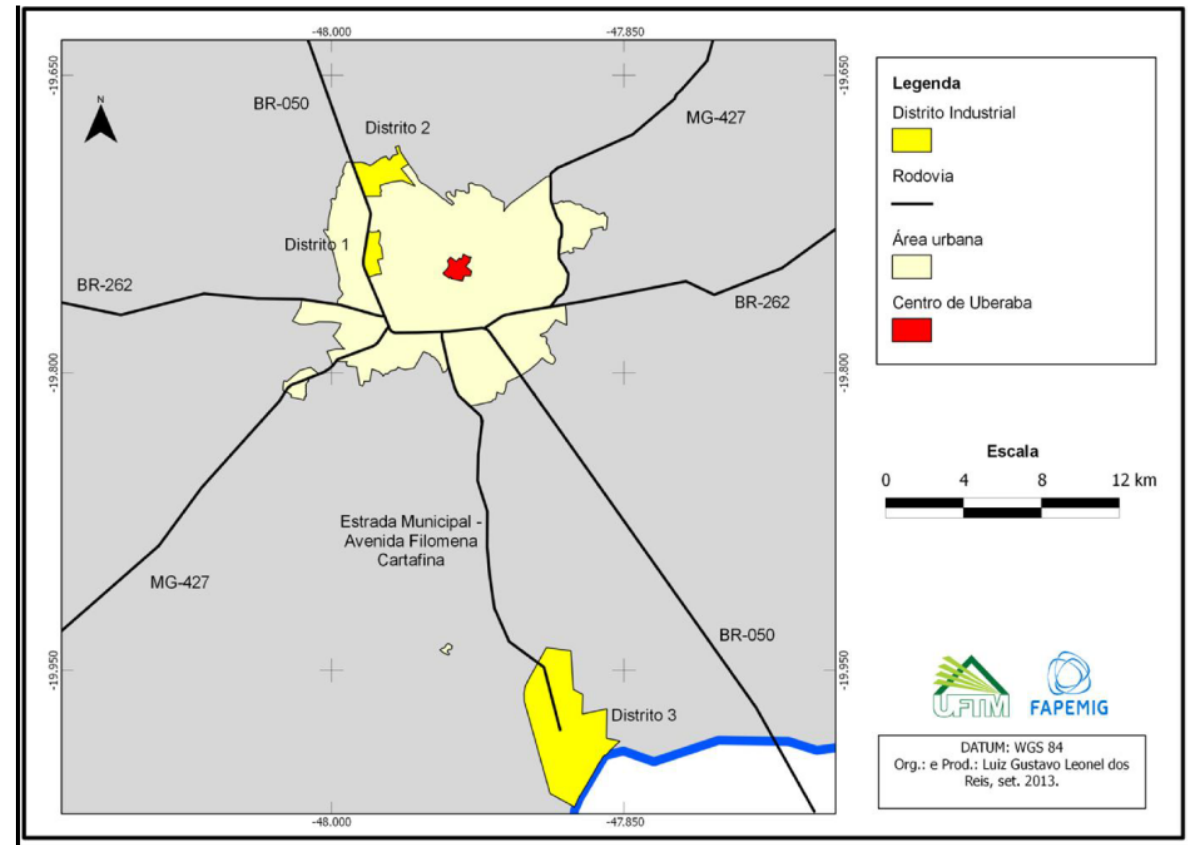

Fonte - GOMES et al, (2013).

\section{CARACTERIZAÇÃO DOS DISTRITOS INDUSTRIAIS DE UBERABA}

Os três distritos industriais existentes no município concentram a maior parte dos estabelecimentos industriais, e foram implantados na década de 1970, a partir de políticas de planejamento promovidas pelo governo federal para atender a expansão do setor agropecuário e também para promover o processo de desconcentração industrial que se iniciou nessa década.

Distrito Industrial I (Figura 2): Inaugurado no ano de $1971 \mathrm{Com}$ uma área de 1.663.913,00 $\mathrm{m}^{2}$, fica a margens da BR 050 a $6 \mathrm{~km}$ do centro do centro de Uberaba, conta com empresas de vários segmentos, química, móveis, elétrica, têxtil e avicultura, contem toda infraestrutura além da localização privilegiada por estar no perímetro urbano da cidade de Uberaba (Quadro 1).

Figura 2 - Distrito Industrial 1 - Uberaba-MG.

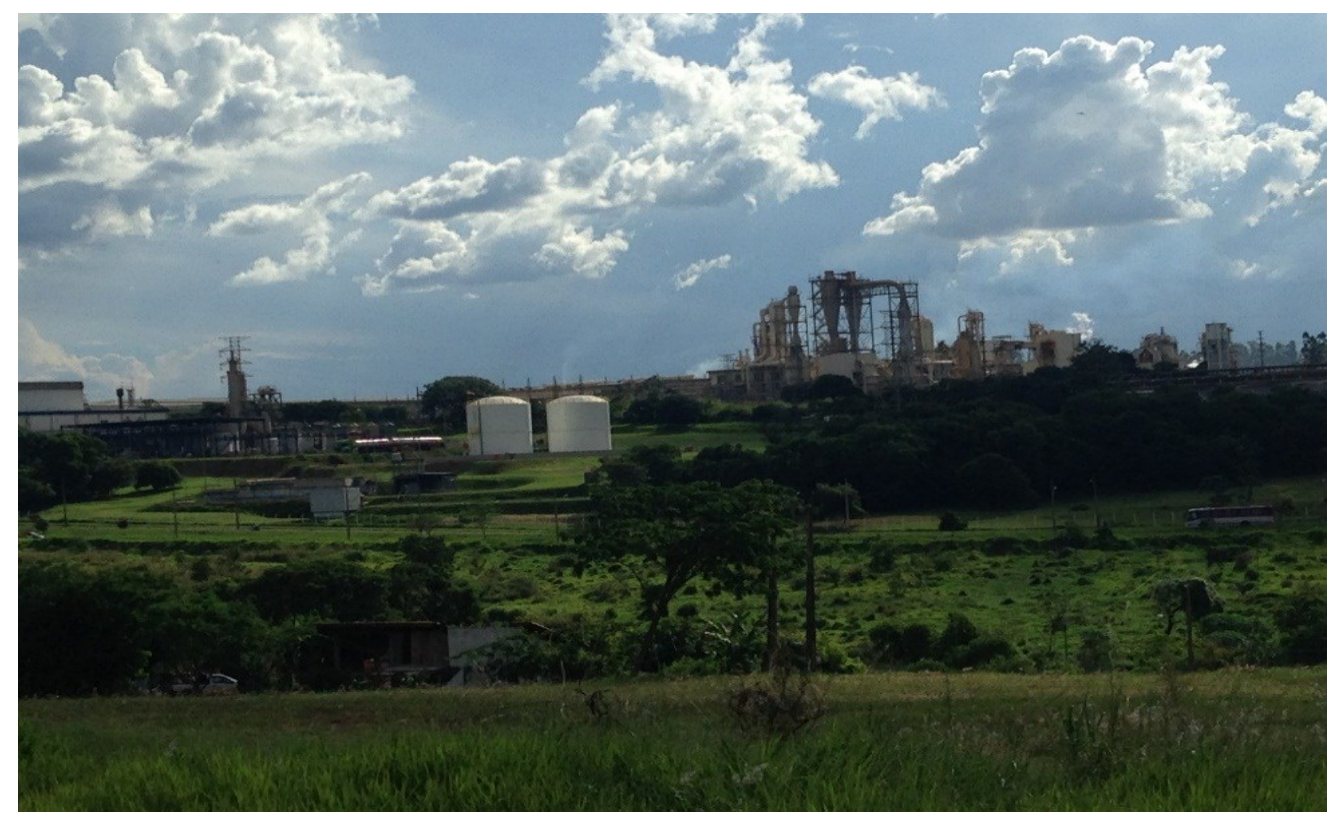

Fonte - Thiago de Jesus Sousa (2018). 
Quadro 1 - Relação de Empresas do Distrito industrial I por Seguimento.

\begin{tabular}{|c|c|}
\hline RAMO DE ATIVIDADE & EMPRESAS \\
\hline Indústria alimentícia & Seara alimentios. \\
\hline Indústria Química & $\begin{array}{l}\text { GPC Química, Mercoquimica, Naq Global química, } \\
\text { Euroforte Agrociências, }\end{array}$ \\
\hline $\begin{array}{l}\text { Fabricação de painéis de } \\
\text { compensados. }\end{array}$ & Duratex \\
\hline Fabricação de maquinas e aparelhos elétricos & $\begin{array}{l}\text { Eletrotécnica grupo AEL, INCEL - Indústria } \\
\text { Nacional de Componentes Elétricos Ltda. }\end{array}$ \\
\hline Fabricação de Alimentos para Animais. & Agrogado, CS Agronegócios \\
\hline Industria da construção civil. & $\begin{array}{l}\text { Brasmix, } \mathrm{S} \& \mathrm{~T} \text { industria e Comércio, geometa } \\
\text { Engenharia, }\end{array}$ \\
\hline Comércio de Recicláveis & CST Ltda. \\
\hline Fabricação de Tintas & Tintas Maggicor, Ultratintas \\
\hline Fabricação de produtos cerâmicos não-refratários. & Eletrocerâmica Indústria de Material Elétrico Ltda, \\
\hline Produção de artefatos estampados de metal. & Eletrometalúrgica Uberaba Ltda. \\
\hline $\begin{array}{l}\text { Comércio atacadista de frutas, verduras, raízes, } \\
\text { tubérculos, hortaliças e legumes frescos. }\end{array}$ & Francisco Puertas Zafra. \\
\hline Coleta de resíduos não perigosos. & Limpebras. \\
\hline Transportadora. & Mantissa Transportes, transplac, transportadora 7B, \\
\hline Fabricação de moveis & $\begin{array}{l}\text { Mobilifício Zago Ltda. Tapeçaria Ribeirão Preto } \\
\text { Ltda. }\end{array}$ \\
\hline Industria mecânica. & Motorque \\
\hline $\begin{array}{l}\text { Aparelhamento de Placas e Execução de } \\
\text { Trabalhos em Mármore, Granito, Ardósia e Outras } \\
\text { Pedras. }\end{array}$ & Serramag mineração. \\
\hline Comércio Atacadista de Bebidas. & $\begin{array}{l}\text { Uberlândia refrescos Ltda ( Coca Cola, Cerveja } \\
\text { Crystal }\end{array}$ \\
\hline $\begin{array}{l}\text { Confecção de peças de vestuário, exceto roupas } \\
\text { íntimas e as confeccionadas sob medida }\end{array}$ & $\begin{array}{l}\text { Zanelatto Indústria e Comércio Ltda. Fabiana de } \\
\text { Lima Bortot- EPP }\end{array}$ \\
\hline $\begin{array}{l}\text { Fabricação de equipamentos para irrigação } \\
\text { agrícola, peças e acessórios }\end{array}$ & Valmont industrial. \\
\hline
\end{tabular}

Fonte - Prefeitura Municipal de Uberaba ( 2018).

No quadro acima podemos observar a variedade de empresas instaladas no Distrito Industrial I, diferente do Distrito Industrial III, os distritos I e II as produções não são voltadas para uma determinada área de atuação, contendo uma economia diversificada, com destaques para empresa Duratex, Valmont e Seara alimentos, mesmo estando dentro do perímetro urbano de Uberaba, possui acesso direto a rodovia BR-050, com acesso direto a c a Brasília e ao estado de São Paulo, além de fazer entroncamento com a rodovia BR-262 com acesso a Belo Horizonte, Vitória e ao estado do Mato Grosso do Sul.

Distrito Industrial II (Figura 3): Com uma área de 1.684.198.00 $\mathrm{m}^{2}$, foi inaugurado em 1978, fica a margem da BR 050 na região noroeste da cidade, há cerca de $7 \mathrm{~km}$ do centro, os seguimentos das empresas ali instaladas são: eletromecânica, moveleiro, agronegócios armazenamento de grãos e fabricas de rações, conforme o Quadro 2. Este distrito possui um ramal ferroviário da empresa (VLI) que faz conexão com diversas regiões do país.

$\begin{array}{lllll}\text { Caminhos de Geografia } \quad \text { Uberlândia-MG } & \text { v. 22, n. } 80 & \text { abr./2021 } & \text { p. 309-323 Página } 319\end{array}$


Figura 3 - Distrito Industrial II.

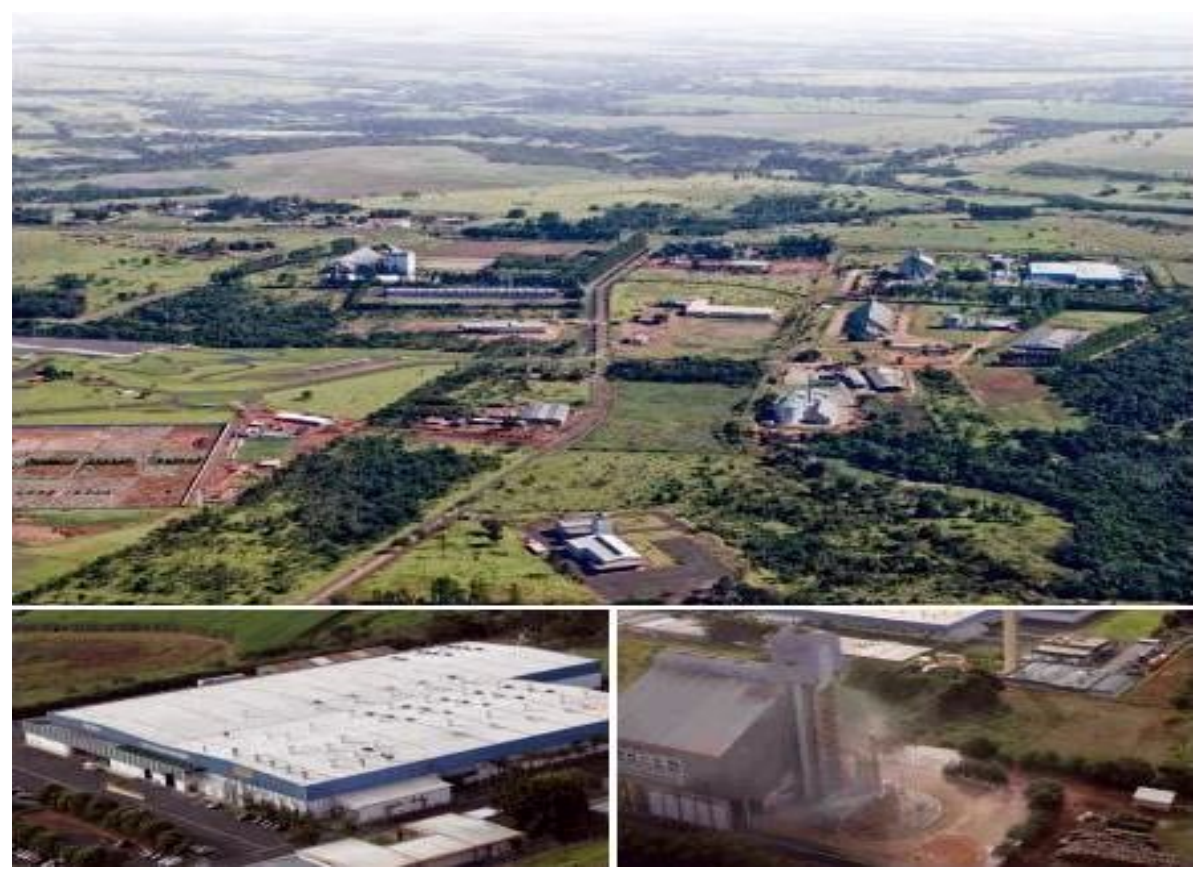

Fonte - Prefeitura Municipal de Uberaba, (2018).

Quadro 2 - Relação de Empresas do Distrito Industrial II por Seguimento.

\begin{tabular}{|c|c|}
\hline RAMO DE ATIVIDADE & EMPRESAS \\
\hline Comércio varejista de madeira e artefatos & Alega ambiental, \\
\hline Comércio varejista de Soja. & $\begin{array}{l}\text { Aliança Agricola do Cerrado, } \text { Produtos } \\
\text { Alimentícios Orlândia S/A }\end{array}$ \\
\hline Armazéns gerais & $\begin{array}{l}\text { Atlas, Casemg, Certrim, EADI Uberaba, } \\
\text { Spasso Armazéns. }\end{array}$ \\
\hline Transportadora & Canabarro Transportes \\
\hline $\begin{array}{l}\text { Pesquisa e desenvolvimento experimental em } \\
\text { ciências físicas e naturais }\end{array}$ & Fundação Triângulo \\
\hline Fabricação de estruturas metálicas & UNIAÇO \\
\hline $\begin{array}{l}\text { Fabricação de cosméticos, produtos de perfumaria } \\
\text { e de higiene pessoal }\end{array}$ & CCM Industria e Comércio. \\
\hline $\begin{array}{l}\text { Fabricação de tubos e acessórios de material } \\
\text { plástico para uso na construção }\end{array}$ & Mexichem Brasil \\
\hline $\begin{array}{l}\text { Fabricação de equipamentos de transmissão para fins } \\
\text { industriais, exceto rolamentos }\end{array}$ & Minas roletes \\
\hline $\begin{array}{l}\text { Fabricação de artefatos de material plástico para } \\
\text { usos industriais }\end{array}$ & Safe Indústria e Comércio Ltda. \\
\hline $\begin{array}{l}\text { Comércio atacadista de produtos alimentícios em } \\
\text { geral. }\end{array}$ & Seara Alimentos. \\
\hline $\begin{array}{l}\text { Fabricação de outros aparelhos eletrodomésticos } \\
\text { não especificados anteriormente, peças e } \\
\text { acessórios. }\end{array}$ & Stanley Black e decker \\
\hline Industrialização e comercialização de Algodão & Ubercotton - Grupo Razera \\
\hline Fabricação de Adubos e fertilizantes. & Ubyfol \\
\hline
\end{tabular}

Fonte - Prefeitura Municipal de Uberaba (2018). 
O Distrito Industrial II, também é formado por empresas de diversas áreas, possui uma grande diversidade de indústrias, sua maior empresa é a Americana Stanley Black e Decker, instalada em 1996, vindo da cidade de Santo André - SP, com mais de 1.100 funcionários, exporta vários produtos para diversos países da América Latina. O Porto Seco do Triângulo criado em 1999,também está instalado nesse distrito. O Distrito Industria II possui uma grande importância voltada no setor de logística e exportação, em destaque diversas empresas voltadas ao armazenamento de grãos como a Casemg, além da empresa química Ubyfol. Assim como o Distrito Industrial I, o Distrito II possui empresas de diversos ramos de atuação.

Distrito Industrial III (Figura 4): Inaugurado no ano de 1979, possui uma área de $18.438 .570 \mathrm{~m}^{2} \mathrm{e}$ está localizado nas proximidades do Rio Grande, na divisa entre os estados de Minas Gerais e São Paulo, há aproximadamente a $20 \mathrm{~km}$ da cidade de Uberaba. O distrito III é o maior do município e conta com grandes empresas da áreas química, fertilizantes, distribuição de combustíveis e transportadoras. No distrito também há um ramal ferroviário da VLI Multimodal S.A.

Figura 4 - Distrito industrial III.

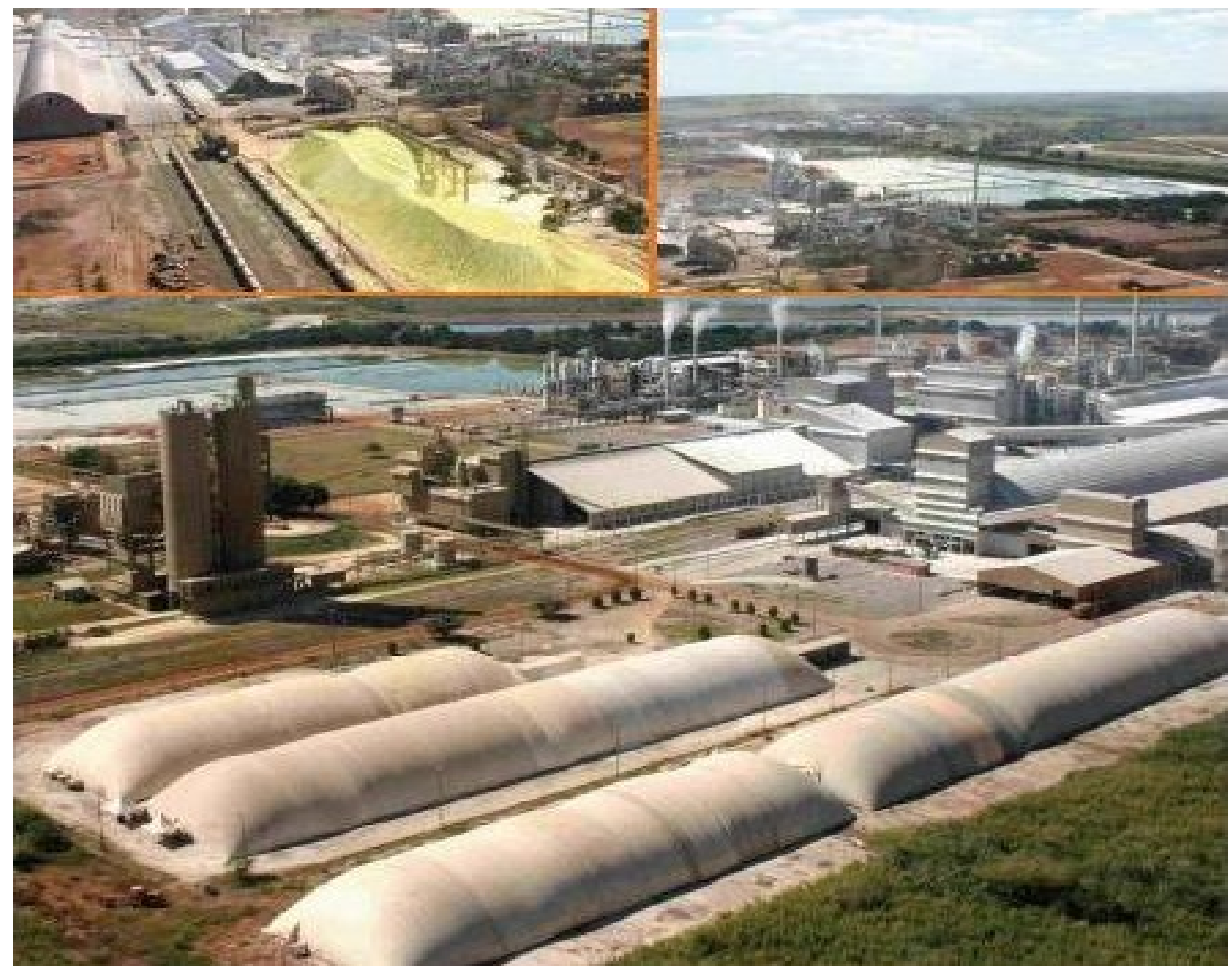

Fonte - Prefeitura Municipal de Uberaba (2018).

O Distrito Industrial III é o maior complexo industrial do município de Uberaba, com a maioria das empresas voltadas para a produção de fertilizantes e produtos químicos, conforme o Quadro 3. Ele possui uma das maiores plantas industriais de Minas Gerais, pertencente a empresa Mosaïc, que adquiriu em ano 2018 a Vale Fertilizantes por cerca de US\$1,150 Bilhões. Atualmente a Mosaïc é 
responsável pelo fornecimento de matéria prima e outros tipos de insumos para a produção de fertilizantes tanto para empresas brasileiras, quanto para exportação. O complexo industrial de Uberaba está interligado com áreas de exploração de rocha fosfática dos municípios de Araxá e Tapira.

Quadro 3 - Relação de Empresa do Distrito Industrial III por seguimento.

\begin{tabular}{|c|c|}
\hline RAMO DE ATIVIDADE & EMPRESAS \\
\hline Manutenção industrial & AGF \\
\hline Fabricação de Adubos e fertilizantes. & $\begin{array}{l}\text { Agronelli, Fertigran, Heringer, Yara Brasil, } \\
\text { Mosaic fertilizantes, consube, agropecuária. }\end{array}$ \\
\hline Distribuidora de combustíveis & $\begin{array}{l}\text { Ale combustíveis, Ciapetro, Ipiranga, } \\
\text { Petrobras, Distribuidora Rio Branco, Royal } \\
\text { Fic, Zema Cia de Petróleo. }\end{array}$ \\
\hline Transportadoras & $\begin{array}{lcc}\text { Transpetro, } & \text { Base transportes, Cocal } \\
\text { Transportes, Guerra e Guerra Transportes, } \\
\text { IC Transportes, JVC Transportes, Lonato } \\
\text { Transportes, Multitrans } & \text { Transportes, } \\
\text { Rodoborges, Rodogran, RZV Minas } & \text { RZ Mran } \\
\text { Transportes, Transcorpa } & \text { transportes, } \\
\text { Transnata, Transolo, } & \text { Transpedrosa, } \\
\text { Transportadora Boa viagem, transportadora } \\
\text { Contato, Transportadora Roma, Venthus } \\
\text { transportes. }\end{array}$ \\
\hline Fabricação de defensivos Agricolas & $\begin{array}{l}\text { Sipcam Nichino, Ourofino química, FMC } \\
\text { Quimica. }\end{array}$ \\
\hline
\end{tabular}

Fonte - Prefeitura Municipal de Uberaba (2018).

\section{CONSIDERAÇÕES FINAIS}

Este artigo abordou o processo de desenvolvimento industrial no município de Uberaba, com destaque para os distritos industriais instalados na década de 1970, a partir de políticas de desenvolvimento criadas pelo Estado na região do Triângulo Mineiro.

A expansão da fronteira agrícola trouxe não só para Uberaba, mas para toda região do Triângulo Mineiro o um modelo de desenvolvimento baseado num processo de industrialização voltado para o setor agropecuário, através de políticas de planejamento do governo federal que visava explorar as áreas de cerrado, que antes eram vistas como improdutivas e ociosas em comparação com as terras de outras regiões do país. O processo de desconcentração industrial, juntamente com a expansão da fronteira agrícola, foram os fatores preponderantes para o crescimento econômico da região do Triângulo Mineiro.

Podemos destacar nesse processo de industrialização do município de Uberaba a importância das indústrias de fertilizantes, instalada no Distrito Industrial III, localizado em uma área próxima às margens do Rio Grande. A ação do Estado foi um dos fatores fundamentais para indústria de fertilizantes no Brasil, assim como as políticas municipais de atração até os dias atuais tiveram um papel fundamental para a atração dessas indústrias, através da isenção de impostos e da oferta de infraestrutura.

O tema abordado nos mostra o crescimento econômico de Uberaba através da industrialização, e como as políticas publicas adotadas pelo governo, possibilitou a exploração de terras através de tecnologias avançadas, e possibilitando um crescimento industrial principalmente através das industrias de fertilizantes que concentra grande parcela da Industria uberabense, a desconcentração industrial também foi um fator muito relevante para todo esse processo, empresas que antes e instalavam somente na RMSP passaram a se instalar em cidades do interior, provocando um crescimento industrial para diversas regiões do Brasil. 


\section{REFERÊNCIAS}

CANO, W. Concentração e desconcentração econômica regional no Brasil:1970-95. Economia e Sociedade, Campinas, v8, p.101-41, jun. 1997.

DINIZ, B. P. C. O Grande Cerrado do Brasil Central: geopolítica e economia. Tese de Doutorado. Departamento de Geografia da FFLCH/USP, Universidade de São Paulo, 2006.

DINIZ, C.C. Estado e capital estrangeiro na industrialização mineira. Belo Horizonte: UFMG/POED, 1981

GOMES, M. T. S.. Cidades Médias e a formação de novos espaços produtivos na rede urbana brasileira: Algumas considerações sobre a cidade de Uberaba-MG/Brasil.XIV Encuentro de Geógrafos de América Latina (EGAL), Lima-Peru, 2013.

GOMES, M. T. S.. Dinâmica econômica e cidades médias: Uma análise sobre a cidade de Uberaba na região do Triângulo Mineiro. Geousp (Online), São Paulo, v.19, n.3, p. 516-534, set./dez. 2015. https://doi.org/10.11606/issn.2179-0892.geousp.2015.81733

GOMES, M.T.S.; MATUSHIMA, M.K.; CHAGAS,N.J. Indústria e dinâmica econômica: alguns apontamentos sobre o setor de fertilizantes em Uberaba - MG. Revista GeoUECE(Online), v.6, n. 10, p.7- 28, jan./jun.2017.ISSN 2317-O28X.

GUIMARÃES, E. N. A influência paulista na formação econômica e social Triângulo Mineiro. In: XI Seminário sobre a Economia Mineira, 2004, Diamantina. XI Seminário sobre a Economia Mineira. Belo Horizonte: CEDEPLAR, 2004.

LEOPOLDI, M. A. P. Política e interesses. As associações industriais, a política econômica e o Estado na industrialização brasileira. São Paulo: Paz e Terra, 2000.

LOURENÇO, L.A.B. O Triângulo Mineiro, do Império à República: o estremo oeste de Minas Gerais na transição para a ordem capitalista (segunda metade do século XIX) .Uberlândia : EDUFU, 2010. https://doi.org/10.14393/EDUFU-978-85-7078-247-2

MAMIGONIAN, A. Teorias sobre a industrialização brasileira. Florianópolis. Cadernos Geográficos Ano II N. 2 - Maio de 2000.

MARKOSKI, A. S. A importância da Função 70 da SUMOC para o desenvolvimento industrial brasileiro durante o segundo governo Vargas (1951-1959). UFRJ: Rio de Janeiro, 2009. (Trabalho de conclusão de graduação, Bacharelado em economia).

MARKUSEN, A. Áreas de Atração de investimentos em um espaço econômico cambiante: Uma Tipologia de distritos. Nova economia: Belo Horizonte, v.5, n.2, dez. 1995.

MARSHALL, A. Princípios de economia: tratado introdutório. São Paulo: Nova Cultural, 1988, 2 ed. (coleção Os Economistas).

MATUSHIMA, M. K.. Especialização produtiva e aglomeração industrial: Uma análise da indústria de confecções de Ibitinga-SP. Tese. Unesp: Rio Claro, 2005, Tese de Doutorado em Geografia.

NEGRI, B. Concentração e desconcentração industrial em São Paulo (1880-1990). Campinas, Editora da Unicamp, 1996.

PAULA, R. Z. A de. Industria em Minas Gerais: origem e desenvolvimento. X Seminário sobre a Economia Mineira. Diamantina, 2002.

PRADO JUNIOR, C. História Econômica do Brasil. São Paulo: Brasiliense, 2006.

PIRES, M. O. Programas agrícolas na ocupação do cerrado. In: Sociedade e Cultura, v.3,n.2, jan/des.2000, p.111-131. https://doi.org/10.5216/sec.v3i1.459

VERSIANI, F.; SUZIGAN, W. O processo brasileiro de industrialização: uma visão geral. In: Congresso InternacionalL de História Econômica, 10, 1990, Louvain. Anais. Louvain 1990.

Recebido em: 23/05/2020

Aceito para publicação em: 18/03/2021 